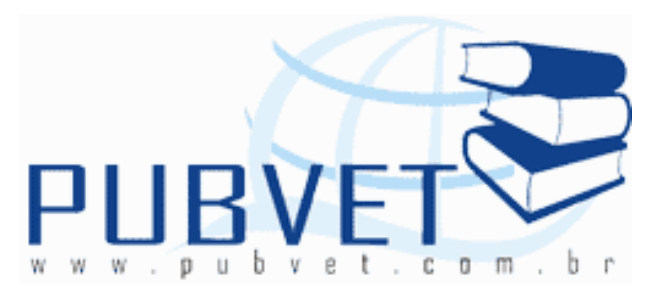

PUBVET, Publicações em Medicina Veterinária e Zootecnia.

\title{
Espécies fúngicas isoladas de ração para gatos comercializadas
}

Indira Portela Barbosa2, Aline Maria Dourado Rodrigues³, Maria Christina

Sanches Muratori ${ }^{1}$, Marcos Daniel de Sousa Ferreira ${ }^{4}$, Francisco das Chagas

Cardoso Filho ${ }^{4}$, Maria Marlúcia Gomes Pereira1*

1 Professora do Departamento de Morfofisiologia Veterinária, Universidade Federal do Piauí(UFPI).* Email: marlucia-gomes@hotmail.com

${ }^{2}$ Graduação em Medicina Veterinária- UFPI

3 Pós-Graduação em Alimentos e Nutrição- UFPI

${ }^{4}$ Pós-Graduação em Ciência Animal- UFPI

\section{Resumo}

A contaminação por fungos nos alimentos podem causar inúmeras perdas econômicas associadas à redução de nutrientes, da palatabilidade e podendo haver à presença de micotoxinas, afetando tanto a saúde humana como a animal. Nesse trabalho objetivou-se avaliar a micobiota da ração de gatos comercializadas em Teresina-PI e verificar se as cepas isoladas são capazes de produzir aflatoxinas. Foram adquiridas 30 amostras de ração, sendo de seis marcas diferentes. Das 30 amostras pesquisadas em apenas oito não foi detectada a presença fúngica. Foi possível isolar espécies de Aspergillus spp. e Penicillium spp., sendo que a espécie mais frequente foi o Aspergillus flavus. Pelo método utilizado foi possível identificar cepas capazes de produzir 
BARBOSA, I.P. et al. Espécies fúngicas isoladas de ração para gatos comercializadas. PUBVET, Londrina, V. 8, N. 15, Ed. 264, Art. 1754, Agosto, 2014.

aflatoxinas. Em rações para gatos comercializadas em Teresina é possível isolar fungos e de encontrar cepas produtoras de aflatoxinas.

Palavras-chave: Alimentação animal, micotoxinas, fungos.

\title{
Fungal species isolated from marketed cat food
}

\begin{abstract}
The fungal contamination in food can cause numerous economic losses associated with the reduction of nutrients, palatability and may be the presence of mycotoxins, affecting both human health and the animal. In this work aimed to evaluate the mycoflora of cat food sold in Teresina-PI and see if the strains are capable of producing aflatoxins. Were acquired 30 samples of diet and six different brands. Of the 30 samples surveyed in eight was not detected the presence of fungal infection. It was possible to isolate species of Aspergillus spp. and Penicillium spp., and the most frequent species was Aspergillus flavus. By the method used was possible to identify strains capable of producing aflatoxins. In diets for cats sold in Teresina is possible to isolate fungi and find aflatoxin producing strains.
\end{abstract}

Keywords: Feed, mycotoxins, fungi.

\section{Introdução}

Ainda hoje a preferência por animais de companhia em sua maioria são por cães e gatos, há uma necessidade de uma alimentação prática e adequada para os animais, as indústrias produtoras de rações para animais de estimação aumentam sua produção a fim de suprir a demanda do mercado consumidor que é cadê vez maior, investindo em equipamentos de alta velocidade de processamento, novas técnicas de produção, utilização de matérias-primas já industrializadas e aditivos complexos, aumentando a possibilidade de riscos à saúde animal. 
BARBOSA, I.P. et al. Espécies fúngicas isoladas de ração para gatos comercializadas. PUBVET, Londrina, V. 8, N. 15, Ed. 264, Art. 1754, Agosto, 2014.

De acordo com estatísticas realizadas no ano de 1994 pelo Sindirações, a produção de alimentos para cães e gatos girou em torno de 220 mil toneladas, a partir do ano 2000 a produção chegou a 1.000 mil toneladas e mais atualmente, no ano de 2011, a produção atingiu aproximadamente 2.130 mil toneladas.

A contaminação por fungos pode causar inúmeras perdas econômicas associadas à redução de nutrientes, da palatabilidade e à presença de micotoxinas, afetando tanto a saúde humana como a animal (SCUSSEL, 2002; PEREIRA et al., 2005). Diversos trabalhos vêm sendo realizados em busca de fungos e micotoxinas em alimentos (CARDOSO FILHO et al., 2011, MURATORI et al., 2011).

Devido a capacidade de produzir micotoxinas, que são metabólitos secundários com potencial de toxicoses ao homem e aos animais, depois de ingeridos $O$ impacto causado por elas abrangem desde a queda na produtividade animal, favorecendo a uma debilidade imunológica, apresentando propriedades alergênicas, teratogênicos, carcinogênicos e mutagênicos .

A presença de fungos nos alimentos animais não significa necessariamente a presença de micotoxinas (PEREIRA et al., 2002), entretanto, quando essas apresentam elevadas contagens fúngicas são consideradas como indicativo da presença de micotoxinas no alimento (FAO, 2004). Existem mais de 100 espécies fúngicas micotoxigênicas, que podem produzir mais de 400 diferentes tipos de micotoxinas. Os principais fungos produtores pertencem aos gêneros: Alternaria, Aspergillus, Fusarium, Penicillium, Rhizoctonia e Stachybotrys, dentre eles destacam-se os gêneros Aspergillus, Penicillium e Fusarium, que são considerados os de maior importância para alimentos e ração, por serem os mais encontrados e os maiores produtores de micotoxinas (PATERSON et. al., 2004; PEREIRA et al., 2005; ROSA et al., 2006; SIMAS et al., 2007; CARDOSO FILHO et al., 2013). No entanto, a maioria ainda não tem 
BARBOSA, I.P. et al. Espécies fúngicas isoladas de ração para gatos comercializadas. PUBVET, Londrina, V. 8, N. 15, Ed. 264, Art. 1754, Agosto, 2014.

claramente definido seu impacto biológico sobre a saúde humana, animal e ao ambiente (KNASMULLER et al., 2004).

Nos últimos anos se tem observado uma intensa expansão na comercialização de rações para animais, impulsionada pela incorporação desta atividade na rotina de Clínicas Veterinárias. As rações comercialmente disponíveis apresentam composições diversificadas, como carne e/ou vegetais, cereais, gorduras, vitaminas e minerais. $O$ conhecimento da biodiversidade fúngica, a detecção da micobiota responsável pela deterioração de cada tipo de alimento e, especificamente associada a produção de micotoxinas, além da análise das principais micotoxinas são fundamentais para que medidas sejam tomadas para o controle da contaminação e, portanto, prevenção de danos diretos ou indiretos à saúde dos pequenos animais.

Este trabalho teve como objetivo avaliar a micobiota fúngica e o potencial toxigênico de fungos do gênero Aspergillus flavus isolados de ração para felinos comercializadas a granel no comércio varejista de Teresina, PI.

\section{Material e Métodos}

Nesse estudo foram utilizadas 30 amostras (300 g cada), sendo essas de cinco marcas diferentes ( $A, B, C, D$ e $E$ ) essas adquiridas em seis estabelecimentos diferentes onde essas eram comercializadas em diferentes pontos na Cidade de Teresina, Brasil. O período de coleta foi entre janeiro e maio de 2011. Após a coleta as amostras foram homogeneizadas, mescladas e quarteladas para a obtenção amostras de $100 \mathrm{~g}$ para o laboratório. A avaliação micológica se iniciou sempre com a chegada das amostras no laboratório de Microbiologia de Alimentos do Núcleo de Estudos, Pesquisas e Processamento de Alimentos (NUEPPA) do Centro de Ciências Agrárias da Universidade Federal do Piauí.

Foram pesadas assepticamente $25 \mathrm{~g}$ de amostra e transferidas para 225 $\mathrm{mL}$ de água peptonada $0,1 \%$ obtendo assim a diluição $10^{-1}$, e a partir desta foram adquiridas as diluições subseqüentes, $10^{-2}$ e $10^{-3}$. 
BARBOSA, I.P. et al. Espécies fúngicas isoladas de ração para gatos comercializadas. PUBVET, Londrina, V. 8, N. 15, Ed. 264, Art. 1754, Agosto, 2014.

De cada diluição, foi transferida alíquotas de $0,1 \mathrm{~mL}$ de cada uma das diluições nos meios de cultivo, tais como: BDA (Batata Dextrose Agar) com ácido tartárico. Depois as placas foram incubadas em estufa a $25{ }^{\circ} \mathrm{C}$ por cinco a sete dias. As placas foram observadas diariamente e selecionadas as que apresentaram contagens entre 10 a 100 unidades formadoras de colônias por grama (ufc/g) (PITT \& HOCKING, 2008).

As colônias dos gêneros Aspergillus e Penicillium foram repicadas e isoladas em MEA (Agar Extrato de Malte) e mantidas em refrigeração até a identificação das espécies.

Para as cepas fúngicas pertencentes ao gênero Aspergillus e Penicillium foram utilizadas as chaves de identificação descritas por KLICH (2002) e PITT (1988) baseadas na semeadura em quatro meios básicos: Czapek Yeast Extract Agar (CYA); Malt Extract Agar (MEA), Czapek Yeast Extract Agar 20\% Sucrose (CY20S) e Glycerol Nitrate Agar 25\% (G25N). Preparou-se uma suspensão de conídios a partir de cada cepa em $0,5 \mathrm{~mL}$ de meio constituído de 0,2\% de agar-agar e 0,05\% de Tween 80TM, distribuído em tubos de hemólise e previamente esterilizados a $121^{\circ} \mathrm{C}$ por 15 minutos (PITT \& HOCKING, 2008). A seguir, introduziu-se a agulha de platina na suspensão de conídios transferindo-os para três pontos eqüidistantes nas placas contendo CYA; MEA, CY20S e G25N. Estas placas foram incubadas por sete dias a $25^{\circ} \mathrm{C}$. Após a incubação, visando à identificação das espécies, observaram-se suas estruturas micromorfológicas e as características macroscópicas das colônias (diâmetro, textura, forma, aspecto da superfície e do reverso, pigmentação dos conídios e pigmento solúvel, produção e cor de exsudado).

A determinação da umidade foi realizada de acordo com metodologia descrita por (BRASIL, 2005), onde procedeu-se a secagem em estufa a $105^{\circ} \mathrm{C}$. A determinação da atividade de água foi realizada em um equipamento modelo Decagon Pawkit $\AA$.

Todas as cepas de Aspergillus flavus foram testadas quanto a capacidade de produzir aflatoxinas, as cepas foram cultivadas em placas MEA e Ágar coco 
BARBOSA, I.P. et al. Espécies fúngicas isoladas de ração para gatos comercializadas. PUBVET, Londrina, V. 8, N. 15, Ed. 264, Art. 1754, Agosto, 2014.

a $25{ }^{\circ} \mathrm{C}$ por 7 dias(LIN \& DIANESE, 1976). As placas foram observadas sob luz UV a $365 \mathrm{~nm}$. O micélio foi transferido para um tubo Eppendorf juntamente com $500 \mu \mathrm{L}$ de clorofórmio. A mistura foi agitada a $4000 \mathrm{rpm}$ por 10 minutos em temperatura ambiente, o micélio foi removido e o extrato de clorofórmio evaporado. O resíduo foi redissolvido em $200 \mu \mathrm{L}$ de clorofórmio. Os extratos foram analisados por cromatografia em camada delgada (CCD) em sílica gel 60 F254, TLC chapas de alumínio (20 x $20 \mathrm{~cm}$, espessura, $250 \mu \mathrm{m}$, Merck, Alemanha). O liquido carreador foi o clorofórmio: acetona $(90: 10 \mathrm{v} / \mathrm{v})$. O limite de detecção do método utilizado é de $5 \mu \mathrm{g} / \mathrm{g}$.

Os resultados foram correlacionados e realizada a análise de variância com significância $(p<0,05)$ utilizando o programa estatístico Sigma Stat (1994).

\section{Resultados e Discussão}

A atividade de água ( $\mathrm{Aw}$ ) das amostras apresentou variação de 0,59 a $0,89 \mathrm{com}$ temperatura entre $22,5^{\circ} \mathrm{C}$ a $25,7^{\circ} \mathrm{C}$. Para umidade constatou-se um valor médio de $8,20 \%$. Sendo uma característica favorável ao desenvolvimento fúngico (FRANCO \& LANDGRAF, 2008).

As análises permitiram a classificação de 2 gêneros, Aspergillus e Penicillium, além de leveduras, que se desenvolveram em $23,3 \%$ das amostras de rações. Em oito amostras de ração não se detectou presença fúngica. As amostras positivas apresentaram níveis de contaminação com contagem variando entre $10^{1}$ e $2 \times 10^{3} \mathrm{UFC} / \mathrm{g}$, não havendo diferença estatística entre as marcas pesquisadas $(P<0,05)$.

Curtis et al.(2011) pesquisando fungos em amostras de rações para cães e gatos. Detectou a presença fúngica em 36 amostras de 50 analisadas $(72 \%)$, semelhantes ao nosso que em $73,3 \%$ estavam positivas.

Bueno et al. (2001), em trabalho realizado na Argentina pesquisando a micobiota em alimentos para cães, encontrou como gênero predominante o 
BARBOSA, I.P. et al. Espécies fúngicas isoladas de ração para gatos comercializadas. PUBVET, Londrina, V. 8, N. 15, Ed. 264, Art. 1754, Agosto, 2014.

Aspergillus spp. (62\%), seguidos por Rhizopus spp. e Mucor spp.,em nosso trabalho o gênero Aspergillus spp. também foi predominante, porém não foram identificados estes outros gêneros, como se pode ver na Tabela 1, mas espécies de Penicillium spp. foram identificadas, isso pode ter sido resultado das condições ambientais.

Tabela 1- Frequência de isolamento de Aspergillus e Penicillium, a partir de rações para gatos comercializada a granel no comércio varejista de Teresina, Piauí.

\begin{tabular}{lll}
\hline Gêneros & $\begin{array}{l}\text { Frequência } \\
\text { absoluta }\end{array}$ & $\begin{array}{l}\text { Frequência } \\
\text { relativa }(\%)\end{array}$ \\
\hline Aspergillus & &
\end{tabular}

A. flavus $\quad 30,0 \quad 81,0$

$\begin{array}{lll}\text { A.niger } & 1,0 & 2,7\end{array}$

Penicillium

$\begin{array}{lrr}\text { P citrinum } & 5,0 & 13,6 \\ \text { P.waksmanii } & 1,0 & 2,7\end{array}$

De acordo com Ribeiro et al. (2003), o gênero Aspergillus é considerado como o principal deteriorador de sementes e grãos, causando danos, descoloração e alterações nutricionais. Russomanno et al. (2002), ao estudarem a presença de fungos em 190 amostras de rações industrializadas, destinadas à alimentação de cães e gatos, observaram a ocorrência de várias espécies de Aspergillus e Fusarium, diferentemente dos nossos resultados que não foi identificado nenhuma cepa de Fusarium.

Em trabalhos realizados por Keller et al.(2005) e Cardoso Filho et al.(2013), analisando rações para eqüinos e peixes respectivamente, 
BARBOSA, I.P. et al. Espécies fúngicas isoladas de ração para gatos comercializadas. PUBVET, Londrina, V. 8, N. 15, Ed. 264, Art. 1754, Agosto, 2014.

obtiveram como principal gênero encontrado o Aspergillus, coincidindo com nosso trabalho.

Pesquisa realizada por Varley (2003) evidenciou a presença de gêneros Aspergillus spp e Penicillium spp em rações para animais em embalagens fechada e abertas que apresentavam pequeno grau de umidade. $O$ autor menciona que esses gêneros são importantes por produzirem micotoxinas conhecidas como aflatoxinas e ocratoxinas, que são de alta toxicidade para os animais, por isso a importância de se pesquisar micotoxinas nos alimentos.

Devido ao alto de índice de cepas de Aspergillus flavus (81\%), essas foram analisadas quanto a produção de aflatoxinas. As cepas foram inoculadas em Ágar coco, das 30 cepas isoladas duas floresceram (cepas 12, 28), foram também testadas em TLC, onde apenas uma cepa (28) demonstrou a capacidade de produzir aflatoxinas, esse resultado demonstrar que de acordo com a técnica empregada, pode-se obter resultados diferentes.

Várias técnicas são empregadas pela indústria na fabricação das rações secas, utiliza-se uma máquina chamada de extrusor, que submete a matériaprima à alta temperatura e pressão, garantindo uma diminuição na carga microbiana do produto final, inclusive fungos, além disso, adicionam microingredientes que visam controlar a proliferação de fungos na ração, por exemplo, a adição de antifúngicos.

Provavelmente as rações armazenadas em sacos abertos e vendidas a granel contaminam-se através do contato com o ar e manuseio, por fungos presentes no ambiente como é o caso dos gêneros Penicillium spp. e Aspergillus spp. que podem facilmente colonizar a ração, especialmente quando a umidade e temperatura forem favoráveis. Um dos principais fatores de controle sobre o desenvolvimento destes fungos em alimentos é a redução da água disponível no substrato, uma vez que é rara a deterioração microbiológica quando os níveis de atividade de água forem inferiores a 0,65 (BERNARDI; NASCIMENTO, 2005). 
BARBOSA, I.P. et al. Espécies fúngicas isoladas de ração para gatos comercializadas. PUBVET, Londrina, V. 8, N. 15, Ed. 264, Art. 1754, Agosto, 2014.

Segundo o Inmetro (2011) as contaminações microbiológicas podem ocorrer devido à utilização de matéria-prima já contaminada no campo ou por questões que envolvem a manipulação, armazenamento e transporte do produto.

Vale ressaltar, porém, que embora a presença de fungos filamentosos nas rações não indique necessariamente contaminação por micotoxinas (PEREIRA, 2002), a presença desses microrganismos funciona como sinalizador dessas toxinas.

Em função destes resultados, recomenda-se que as rações comercializadas a granel sejam mantidas em sacos semi-fechados, com controle de umidade e exposição para evitar o aumento das contaminações por fungos, além de estarem dentro do prazo de validade.

É importante que haja acompanhamento e orientação aos comerciantes ligados diretamente a venda de rações para gatos, tendo em vista a qualidade e segurança para seu produto.

\section{Conclusão}

Com esse trabalho pode-se concluir que é possível encontrar cepas fúngicas produtoras de aflatoxinas em rações para gato.

\section{Referências Bibliográficas}

ANDRADE, R. M.; NASCIMENTO, J. S. Presença de fungos filamentosos em ração para cães comercializadas na cidade de Pelotas - RS, 2002. UFPEL.

BRASIL. Ministério da Saúde. Agência Nacional de Vigilância Sanitária. Métodos físico-químicos para análise de alimentos. Brasília: Ministério da Saúde, 2005. 1018p.

BERNARDI, E.; NASCIMENTO, J.S. do. Fungos Anemófilos na praia do Laranjal, Pelotas, Rio Grande do Sul, Brasil. Arq. Inst. Biol.,São Paulo, v.72, n.1, p.93-7, 2005.

BUENO, D. J. et al. Mycoflora in commercial pet foods. Journal of Food Protection, v. 64,n. 5, p. 741-743, 2001.

CARDOSO FILHO, F.C.; CALVET, R.M.; PEREYRA, C.M.; PEREIRA, M.M.G.; ROSA, C.A.R.; TORRES, A.M.; MURATORI, M.C.S. Ocorrência de Aspergillus spp., e Penicillium spp. e 
aflatoxinas em amostras de farinha de milho utilizado no consumo humano, Piauí, Brasil. Arq. Inst. Biol., São Paulo, v.78, n.3, p.47-51, jul./set., 2011

CARDOSO FILHO, F.C.; CALVET, R.M.; ROSA, C.A.R.; PEREIRA, M.M.G.; COSTA, A.P.R.; MURATORI,M.C.S.Monitoramento de fungos toxigênicos e aflatoxinas em rações utilizadas em piscicultura. Ciênc. anim. Bras. Vol.14 no.3 Goiânia July/Sept. 2013

CURTIS, A. O.; BESS, F.; SILVEIRA F.; SANTURIO, J. M.; FERREIRO, L. Comparação de diferentes meios de cultivo para avaliação micológica de rações comerciais para cães e gatos. Disponível em: <http://www.sovergs.com.br/conbravet2008/anais/cd/resumos/R11152.pdf. >. Acesso em: 08 ago. 2011.

FAO.Almacenaje.2004.Disponível em:<http://www.fao.org> Acessado em: 23 set. 2012

FONSECA, $H$. Os fungos e a deterioração de alimentos. Disponível em: < http://www.micotoxinas.com.br/boletim4.htm>. Acesso em: 13 mai. 2011.

FRANCO, B.D.G.M.; LANDGRAF, M. Microbiologia dos Alimentos. São Paulo:Atheneu, 2008. $182 p$.

GIMENO, A. Revision genérica Del problema de los hongos y de lãs micotoxinas em al alimentacion animal. Disponível em: http://www.engormix.com/los_hongos_micotoxinas_alimentacion_s_articulos_362_MYC.htm>. Acesso em 5 mai. 2011.

INMETRO, Ração para cães e gatos. Disponível em: http://www.inmetro.gov.br/consumidor/. Acesso em: 02/07/2011.

KELLER, M. K; QUEIROZ, B. Q.; KELLER L, A. M.; RIBEIRO, J. M. M.; ROSA, C. A. R. Isolados de amostras de rações destinadas a alimentação de equinos no Estado do Rio deJaneiro. Revista Universidade Rural Série Ciências da Vida, v. 25, n. 1, p. 93-96, 2005.

$\mathrm{KLICH}, \mathrm{M}$. A. A laboratory guide to the common Aspergillus species and their teleomorphs. CSIRO - Division of Food Processing, Australia, 2002. 116p.

KNASMULLER S.; CAVIN C.; CHAKRABORTY A.; DARROUDI F.; MAJER B.; HUBER.W.; EHRLICH V.; "Structurally Related Mycotoxins Ochratoxin A, Ochratoxin B, and Citrinin Differ in Their Genotoxic Activities and in Their Mode of Action in Human- Derived Liver (Hep G2) Cells: Implications for Rick Assessment"; Nutrition and Cancer, 50(2): 190-197, 2004

LIN, M. T.; DIANESE, J. C. A coconut-agar medium for rapid detection of aflatoxin production by Aspergillus spp. Phytopathology, v. 66, n. 12, p. 1466-1469, 1976.

MURATORI, M.C.S.; CASTRO, P.L.; LEAL, D.I.B.; COSTA, A.P.R.; PEREIRA, M.M.G.; CARDOSO FILHO, F.C. Fungos na massa para preparo de fishburgere e seus ingredientes. Acta Veterinaria Brasilica, v.5, n.4, p.399-404, 2011

PATERSON, R. R. M.; VENÂNCIO, A.; LIMA, N. Solutions to Penicillium taxonomy crucial to mycotoxin research and health. Research in Microbiology. 155(7):507- 513, 2004

PEREIRA, M.M.G., CARVALHO, E.P., PRADO, G. Crescimento e produção de aflatoxinas por aspergillus flavus e aspergillus parasiticus. B. CEPPA, 20(1):2002.

PEREIRA, M. M. G. Aflatoxinas em alimentos destinados a bovinos e em amostras de leite da região de Lavras, Minas Gerais - Brasil, Ciênc. agrotec., Lavras, v. 29, n. 1, p. 106-112, jan./fev. 2005.

PITT, J.I. A Laboratory guide to commom Penicillium species. 2.ed. North Ride: CSIRO Division of Food Processing, 1988. 186p.

PITT, J.I; HOCKING, A.D. Fungi and Food Spoilage. 2. edition. London: Blackie academic and Professional, 2008. 593p. 
RIBEIRO, S.A.A.L.; CAVALCANTI, M.A.Q.; FERNANDES, M.J.S. e LIMA, D.M.M. Fungos filamentosos isolados de produtos derivados do milho comercializados em Recife, Pernambuco. Revis. Brasil. Bot., vol. 26, n.2, p. 223-229. 2003.

ROSA, C. A.R. RIBEIRO, J.M.M.; FRAGA, M.J.; GATTI, M.; CAVAGLIERI, L.R.; MAGNOLI, C.E.; DALCERO, A.M.; LOPES, C.W.G. Mycoflora of poultry feeds and ochratoxin-producing ability of isolated Aspergillus and Penicillium species. Veterinary Microbiology, v. 113, n.1-2, p.89-96, 2006.

RUSSOMANNO, O.M.R.; ISIKAWA, P.M.; VALESAN, A.M.C.; MELINSKI, A.R.; HIPÓLITO, M. Fungos toxigênicos presentes em rações industrializadas destinadas à alimentação de cães e gatos. Arquivos do Instituto Biológico, São Paulo, v.69, p.85, 2002. Suplemento. REUNIÃO ANUAL DO INSTITUTO BIOLÓGICO, 15., 2002, São Paulo, Resumo 122.

SCUSSEL, V.M. (2002). Fungos em grãos armazenados. In: Lorini, I., Miike, LH, Scussel, VM Armazenagem de grãos. IBG (Campinas, São Paulo, Brasil), 675-804.

SIMAS, M. M.; BOTURA M. B.; CORREA, B. Determination of fungal microbiota and mycotoxins in brewers grain used in dairy cattle feeding in the State of Bahia, Brazil. Food Control, v.18, p. 404-408, 2007.

SIGMA STAT for windows version 1.0. Jandel Corporation, 1994.

VARLEY, M. Where are we now with control of mycotoxins? Pig Progress, v. 20, n. 10, p. 2425, 2004. Disponível em: <http://www.pigprogress.net/pigs/ disease-management/wherearewe-now-with-control-of-mycotoxins\%3F-5007.html>. Acesso em: 23 out. de 2011. 